\title{
Intimate partner violence (physical and sexual) and sexually transmitted infection: results from Nepal Demographic Health Survey 20I I
}

This article was published in the following Dove Press journal:

International Journal of Women's Health

20 January 2014

Number of times this article has been viewed

\section{Liladhar Dhakal}

Gabriele Berg-Beckhoff

Arja R Aro

Unit of Health Promotion Research, University of Southern Denmark,

Esbjerg, Denmark
Correspondence: Liladhar Dhakal Unit of Health Promotion Research, University of Southern Denmark, Esbjerg, Denmark

Tel +9779845358623

Email liladhardhakal@gmail.com
Introduction: Violence against women perpetrated by their intimate partners is a social problem with adverse health consequences. Intimate partner violence has acute and chronic as well as direct and indirect health consequences related to physical, psychological, and reproductive health. Studies exploring relationships of intimate partner violence and health consequences are rare in Nepal. Hence, this study aimed to examine the relationships between intimate partner violence and sexually transmitted infections.

Method: This study used data from the nationally representative Nepal Demographic Health Survey 2011, which collected data through a two-stage complex sampling technique. Women 15-49 years were asked about domestic violence including intimate partner violence. For this analysis, 3,084 currently married women were included. Questions about domestic violence were adapted from the Conflict Tactic Scale. Relationships between different forms of physical and sexual intimate partner violence and reported signs and symptoms of sexually transmitted infections were examined using multiple logistic regression analysis.

Results: Approximately $15 \%$ of currently young and middle-aged married women experienced some form of violence in the last 12 months. About one in four women who were exposed to physical and sexual intimate partner violence reported sexually transmitted infection in the last 12 months. The odds of getting sexually transmitted infection were 1.88 [95\% CI:1.29, 2.73] times higher among women exposed to any form of intimate partner violence in the last 12 months compared to women not exposed to any form of intimate partner violence.

Conclusion: Intimate partner violence was common among currently married women in Nepal. Being exposed to intimate partner violence and getting signs and symptoms of sexually transmitted disease were found to be associated. Integration of intimate partner violence prevention and reproductive health programs is needed to reduce the burden of sexually transmitted disease among currently married women.

Keywords: intimate partner violence, socio-demographic, sexually transmitted disease, Nepal

\section{Introduction}

Intimate partner violence (IPV) is one of the major public health issues currently facing human society. The World Health Organization (WHO) defines IPV as "any behavior within an intimate relationship that causes physical, psychological and sexual harm to those in the relationship." IPV is prevalent in all human societies irrespective of religion, socioeconomic status, and culture. ${ }^{1}$ A study conducted by the WHO reported that the magnitude of IPV against women varied among countries depending on their developing status; for example, $61.7 \%$ of women in Bangladesh and $15.4 \%$ of women in Japan experienced IPV in their lifetime. ${ }^{2}$ 
Various small scale-studies have documented wide ranges of IPV prevalence in Nepalese women. A cross sectional study conducted among 1,296 rural married women of 15-24 years of age representing four major ethnic groups of four districts (Dolkha, Sindhupalchowk, Dang, and Kapilbastu) in Nepal reported that $46 \%$ had experienced sexual violence from husbands at some point of life and $31 \%$ experienced sexual violence in the last 12 months. ${ }^{3}$ Another cross sectional study among 1,536 reproductive age married women of four districts (Achham, Gulmi, Rupendehi, and Ilam) reported that $58 \%$ had experienced sexual violence from their husbands at some point in their lives. ${ }^{4}$ Similarly, another study interviewed 791 married women of reproductive age from rural parts of six districts (Dadeldhura, Nawalparasi, Makwanpur, Siraha, Sindhupalchowk, and Sankhuwashava) of Nepal revealed that $16.6 \%$ experienced sexual violence from intimate partners at any point of life and $7.1 \%$ had sexual violence from an intimate partner in the last 12 months. ${ }^{5}$ According to the Nepal Demographic Health Survey (NDHS) in 2011, 21.5\% and $12.3 \%$ of women aged 15-49 experienced physical and sexual violence in their lifetime. Furthermore, sexual violence was more prevalent among divorced, separated, or widowed women (22\%) compared to currently married (15\%) and never-married women (2\%). NDHS 2011 revealed that a third of married women experienced some form of violence from their husbands at any point in their lives. ${ }^{6} \mathrm{~A}$ large range of IPV prevalence was reported in Nepal by various studies, mainly due to the purposive selection of the study districts and samples collected only from rural parts. ${ }^{3-5}$ Studies other than NDHS were confined to some ethnic groups or age groups or a few districts of Nepal and their results cannot be generalized for the whole country.

IPV has various health effects, including acute and chronic as well as direct and indirect health problems related to physical, psychological, and reproductive health. ${ }^{7-12}$ Sexual risk taking, unplanned pregnancy, multiple partners, sexually transmitted infections (STIs), abortion or miscarriage, depression, prenatal substance use, and low birth-weight were found to be associated with IPV. ${ }^{7-12}$ A systematic review showed that IPV was associated with STI but also with unplanned pregnancy, sexual risk taking, inconsistent condom use, partner non-monogamy, abortion, and sexual dysfunction. ${ }^{13}$ Abusive partners may have risky sexual behaviors, including multiple partners, and abused women may not be able to negotiate for safer sex, which may result in STI transmission. ${ }^{13}$

A cross-sectional study of six countries reported a higher risk of STI among currently married women exposed to
IPV compared to those not exposed. ${ }^{7}$ Risk of STI among adolescent women who had experienced IPV was 2.1 times the risk of adolescents who did not experience IPV. ${ }^{14} \mathrm{~A}$ clinicbased case control study in Australia reported higher risk of STI among those exposed to IPV compared to those not exposed to IPV. ${ }^{15} \mathrm{~A}$ survey among African-American women aged 18-29 years revealed higher risk of confirmed STI positive test among those exposed to IPV compared to those not exposed to IPV.$^{16} \mathrm{~A}$ nested case-control study showed a higher risk of confirmed syphilis among those exposed to IPV compared to those not exposed. ${ }^{17} \mathrm{~A}$ randomized controlled trial among women aged 13-35 years based on computer based intervention to compare two different methods of counseling to promote the use of dual methods of contraception reported association (hazard rate ratio 1.68) between STI incidence and history of IPV in the past year. ${ }^{18}$

Very few studies have been conducted about IPV and its health impact in Nepal. Among them, NDHS 2011 was the first that provided nationally representative information. A study based on the data of NDHS 2011 reported an association between physical and/or sexual IPV and childhood anemia. ${ }^{19}$ To the best of our knowledge, no study examining the relationship between IPV and STI has been carried out in Nepal. This study aims to assess the relationship between IPV and likely STI. In the context of lack of country-specific evidence about the relationship of IPV with STI, this study will give insight on how IPV affects the sexual health of Nepalese women. The results will provide contextual evidence for policy and program development to improve the sexual health status of women in Nepal.

\section{Methodology \\ Sample}

This analysis is based on the nationally representative cross-sectional sample survey, NDHS 2011, conducted from February 2 to June $14,2011.6$ The survey used a two stage stratified cluster sampling strategy; details of the sampling procedure have been reported elsewhere. ${ }^{6}$ Besides family planning, maternal and child health and HIV/AIDS related information, information about domestic violence was collected for the first time in NDHS 2011. ${ }^{6} \mathrm{Nepal}$ is divided into 75 districts and each district has village development committees (VDC) and/or municipalities. VDCs and municipalities are further divided into wards. In municipalities, larger wards are divided into sub-wards. In NDHS, wards of VDCs and sub-wards of the municipalities were treated as enumeration areas (EA). For the sampling purpose, Nepal was divided into 25 strata. In each stratum, EAs were selected using 
probability proportionate to size strategy. Each and every household of all selected EAs was listed and mapped. Then, 35 households from urban and 40 households from rural EAs were selected randomly. NDHS used household questionnaires to identify women eligible for the individual interview. Among selected households, a domestic violence module of the questionnaire was administered to every second household. From each selected household, only one woman was included for the domestic violence module. ${ }^{6}$ Written consent was taken from each respondent before interview. ${ }^{6}$ Ethical approval was obtained from the Nepal Health Research Council, Nepal and IFC Macro Institutional Review Board in Calverton, MD, USA. We obtained permission to use data from the ICF international. Figure 1 describes the selection of the sample for this study and provides un-weighted numbers of women.

\section{Measures}

The area of interest in this analysis was IPV and comprised either physical and/or sexual violence against the wife perpetrated by the husband in the last 12 months preceding the survey. Data were collected by using a "shortened and modified version of Conflict Tactic Scale." ${ }^{20}$ To assess the status of physical violence, women were asked whether their husbands pushed, shook, or threw something at them; slapped; twisted their arm, or pulled their hair; punched; kicked, dragged, or beat them; choked, burned, threatened, or attacked them with a knife, gun, or any other weapon. Similarly, sexual violence was assessed by asking whether their husband physically forced them to have sexual intercourse and forced them to perform some sexual act when they did not want to. A positive answer to any of the above seven items of physical and/or any one of two items of sexual violence in the last 12 months indicated the existence of any IPV. Though NDHS 2011 had collected additional information about emotional violence, we considered

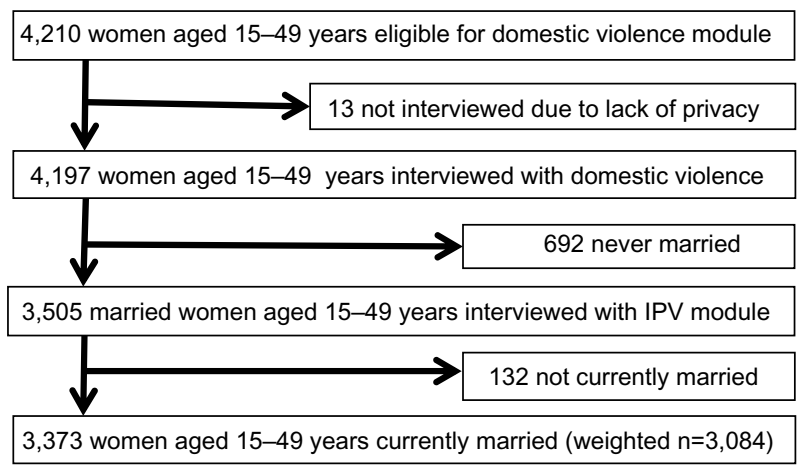

Figure I Sampling scheme of the study. Abbreviation: IPV, intimate partner violence. only physical and sexual violence in this study. Compared to emotional violence, physical and sexual violence has been defined more clearly and measured more precisely. ${ }^{19}$

Information about STI in the last 12 months was collected by asking whether women contracted a disease through sexual contact or had a bad-smelling abnormal genital discharge or had a genital sore/ulcer in the last 12 months. Positive response to at least one of above three questions was treated as having an STI in the last 12 months. Nepal is divided horizontally into three regions (Mountain, Hill, and Terai) and vertically into five regions (Eastern, Central, Western, Midwestern, and Far-western). Women were broadly grouped into five caste groups (Brahman/Chhetri, Janajati, Dalit, other Terai caste, and Muslim).

\section{Analysis}

STATA 12 (StataCorp LP, College Station, TX, USA) was used to analyze the data. Simple descriptive information was given for socio-demographic status and prevalence of any IPV and STI by background characteristics of the women. Chi-square test was carried out to explore the distribution difference of women in different categories of exposure, confounders, and outcomes. Multiple logistic regressions were carried out to explore the relationships between the IPV and STI in the last 12 months with adjustment for possible confounders. Respondents having symptoms of STI were coded as 1 and those without symptoms of STI were coded as 0. Similarly, respondents who experienced IPV were coded as 1 and those who had not experienced IPV were coded as 0 . The following confounders were considered: age, caste, education, and occupation of the woman; occupation, education, and drinking habits of the husband; number of marriages, presence of other wives, economic status, and attitudes toward negotiation for safer sex. Before doing the analysis, the data set was first declared as "survey data set" and the "svy" command was used to take into account cluster sampling design, sampling weights, and the calculation of standard error. The Taylor linearization method was used to estimate the standard error and confidence intervals. Sampling weights calculated for the domestic violence were used as per the guidance of final report of NDHS 2011. ${ }^{20}$ Crude and adjusted odds ratios (OR) were presented with $95 \%$ confidence interval (CI) and $P$-value.

\section{Results Background characteristics of the currently married women}

About three in ten women were 15-24 years of age (Table 1). Most women were from the Hill region followed by the Terai. 
Table I Distribution of women and prevalence of any IPV and STI in the last 12 months by the women's background characteristics $(\mathrm{NDHS} 20 \mathrm{II})^{6,32}$

\begin{tabular}{|c|c|c|c|c|c|}
\hline \multirow{2}{*}{$\begin{array}{l}\text { Background } \\
\text { characteristics }\end{array}$} & \multicolumn{2}{|l|}{ Any IPV } & \multirow[t]{2}{*}{$P$-value } & \multirow{2}{*}{$\frac{\text { STI }}{\%(95 \% \mathrm{Cl})}$} & \multirow[t]{2}{*}{$P$-value } \\
\hline & Total n (\%) & $\%(95 \% \mathrm{Cl})$ & & & \\
\hline \multicolumn{6}{|l|}{ Age of women } \\
\hline 15-24 years & $880(28.56)$ & $16.55(13.46,20.17)$ & 0.2250 & $12.28(9.09,16.38)$ & 0.2063 \\
\hline $25-34$ years & I,085 (35. I7) & $14.83(12.14,17.99)$ & & $16.19(13.55,19.22)$ & \\
\hline $35-49$ years & 1,119 (36.27) & $12.94(10.76,15.49)$ & & $15.05(12.48,18.03)$ & \\
\hline \multicolumn{6}{|l|}{ Caste } \\
\hline Brahman/Chhetri & I,224 (39.68) & $10.39(8.54,12.58)$ & 0.0001 & |4.4| (II.9|, |7.32) & 0.3139 \\
\hline Janajati & I,077 (34.9I) & $14.63(12.07,17.62)$ & & $12.75(10.29,15.70)$ & \\
\hline Dalit & 491 (I5.94) & $21.84(17.04,27.55)$ & & I9.23 (I3.58, 26.5I) & \\
\hline Other Terai caste & $198(6.42)$ & $17.35(10.88,26.5 \mathrm{I})$ & & I $5.95(8.48,27.98)$ & \\
\hline Muslim & $95(3.07)$ & $26.50(15.68,41.14)$ & & I3.06 $(6.67,24.02)$ & \\
\hline \multicolumn{6}{|l|}{ Place of residence } \\
\hline Urban & $746(24.21)$ & I5.88 (I2.80, 19.55) & 0.3834 & I5.67 (I2.63, 19.29) & 0.5039 \\
\hline Rural & 2,338 (75.79) & $14.24(12.52,16.15)$ & & $14.33(12.23,16.72)$ & \\
\hline \multicolumn{6}{|l|}{ Ecological region } \\
\hline Mountain & $319(10.34)$ & $13.35(10.14,17.37)$ & 0.0208 & $12.30(9.11,16.40)$ & 0.3414 \\
\hline Hill & I,449 (46.98) & $12.69(10.42,15.36)$ & & I5.88 (|3.2।, |8.96) & \\
\hline Terai & I,316 (42.67) & $17.09(14.77,19.70)$ & & $13.89(11.15,17.16)$ & \\
\hline \multicolumn{6}{|l|}{ Development region } \\
\hline Eastern & $688(22.32)$ & I5.54 (I2.00, 19.88) & 0.1968 & $19.25(15.36,23.84)$ & 0.0627 \\
\hline Central & I,030 (33.38) & $13.60(11.16,16.49)$ & & I3.88 (I0.83, I7.6I) & \\
\hline Western & $320(10.36)$ & $10.15(7.54,13.52)$ & & $14.27(10.63,18.89)$ & \\
\hline Mid-western & $499(16.20)$ & $16.92(\mid 3.84,20.5 I)$ & & |4.72 (II.3।, |8.93) & \\
\hline Far-western & $547(17.74)$ & $15.98(11.88,21.16)$ & & $10.52(6.61,16.34)$ & \\
\hline \multicolumn{6}{|l|}{ Economic status } \\
\hline Poor & $638(20.69)$ & I8.37 (I4.54, 22.94) & 0.0250 & $12.47(9.57,16.10)$ & 0.1455 \\
\hline Not poor & $2,446(79.31)$ & $13.66(12.05,15.45)$ & & I5.23 (|3.28, I7.40) & \\
\hline \multicolumn{6}{|l|}{ Number of marriages } \\
\hline One & $2,922(94.74)$ & $13.65(12.09,15.38)$ & 0.0001 & $13.89(12.13,15.87)$ & 0.0001 \\
\hline More than one & $162(5.26)$ & $32.34(23.44,42.74)$ & & $28.39(20.08,38.49)$ & \\
\hline \multicolumn{6}{|c|}{ Attitude towards negotiation for safer sex } \\
\hline Positive & $2,964(96.10)$ & $14.2(|2.64| 5.9 \mid)$, & 0.0022 & $14.72(\mid 2.86,16.80)$ & 0.6108 \\
\hline Negative & $120(3.90)$ & 25.45 (I7.9I, 35.8I) & & I $3.09(8.42,19.80)$ & \\
\hline \multicolumn{6}{|l|}{ Women's occupation } \\
\hline No work & $653(21.16)$ & I4.09 (I0.6I, I8.49) & 0.0011 & $14.15(10.72,18.45)$ & 0.8413 \\
\hline Agriculture & I,834 (59.45) & $14.52(12.48,16.82)$ & & $14.17(11.90,16.78)$ & \\
\hline Professional & $128(4.15)$ & $6.43(2.94,13.46)$ & & $17.66(10.37,28.43)$ & \\
\hline Sales/services & $284(9.22)$ & I2.22 (8.35, I7.52) & & I6.54 (I I.82, 22.68) & \\
\hline Manual & $186(6.02)$ & $27.05(20.01,35.47)$ & & $16.30(9.95,25.57)$ & \\
\hline \multicolumn{6}{|l|}{ Women's education } \\
\hline No education & I,48I (48.00) & $18.43(16.00,21.13)$ & 0.0001 & $|5.4|(|2.78| 8.48)$, & 0.1190 \\
\hline Primary & $563(18.28)$ & $13.64(10.80,17.07)$ & & II.25 (8.76, I4.34) & \\
\hline Secondary/higher & $\mathrm{I}, 040(33.72)$ & $9.78(7.68,12.38)$ & & $15.42(|2.78| 8.49)$, & \\
\hline
\end{tabular}

Note: Taylor linearization method was used to estimate the standard error and $P$-value was calculated by Pearson chi-squared test.

Abbreviations: $\mathrm{Cl}$, confidence interval; IPV, intimate partner violence; NDHS, Nepal Demographic Health Survey; STI, sexually transmitted infection.

Three in ten were from the central development region, one in ten from the western development region, and three in four resided in the rural region (Table 1). About a half of the respondents had no education, one in 20 had been married more than once and one in 25 was living with cowives. Agriculture was the occupation of six in ten women (Table 1).
About $15 \%$ of currently married women were exposed to at least one form of violence in the 12 months preceding the survey (Table 1). One in four Muslims and one in five Dalit women had experienced some form of IPV in the last 12 months preceding the survey. Women from the Terai region, from poor households, with no education, who worked manual jobs, had been married more than once, and those who lived 
with co-wives had a higher prevalence of IPV compared to their counterparts (Table 1). About $15 \%$ of women had STI in the 12 months preceding the survey (Table 1). Women who had been married more than once and who had experienced any form of violence in the 12 months preceding the survey had a significantly higher prevalence of STI compared to their counterparts (Table 1).

Women, whose husbands had no education, had manual jobs, who lived with several wives, and drank alcohol experienced more IPV. No husband characteristics were found associated with prevalence of STI (Table 2).

The association between IPV and STI is shown in Table 3. About $23 \%$ of women exposed to IPV and $13 \%$ of women not exposed to IPV had suffered from STI in the last 12 months (Table 3).

\section{STI by IPV exposure status and other background characteristics}

The crude OR of having STI in the last 12 months for women exposed to any IPV in the last 12 months was two times higher (OR: 1.96; 95\% CI: 1.38, 2.77) compared to unexposed women; the multiple logistic regression analysis revealed similar results (OR: 1.88; 95\% CI: 1.29, 2.73). The result was statistically significant with a $P$-value less than 0.01 (Table 4). Analysis also revealed that the risk of getting STI was 2.50 times higher among women married more than once and 0.65 times lower among women with primary education compared to those married once and to those who had no education (Table 4).

\section{Discussion}

Women who experienced any form of IPV in the last 12 months had about two times higher risk of getting STI compared to those who did not have IPV even after adjustment for possible confounders like age, caste, education, and occupation of the woman; occupation, education, and drinking habits of the husband; number of marriages, presence of other wives, economic status, and attitude towards negotiation for safer sex. The findings of this study were consistent with results of other studies including systematic reviews of observational studies and clinical trials..$^{7,15,16,18}$ Various studies based on self-report of STI also reported higher odds of getting STI among women who experienced IPV compared to those not exposed. ${ }^{7,21,22}$ A randomized controlled trial based on computer-based intervention reported higher incidence of STI (hazard rate ratio 1.68) among women who were exposed to IPV compared to those not exposed. ${ }^{18}$ Another case control study also reported higher odds with a history of getting STI among those exposed to IPV. ${ }^{15}$ A clinic-based study among African-American women also reported higher odds of being STI test positive among women who had a history of IPV compared to women who had no history of IPV. ${ }^{16}$

Furthermore, about $15 \%$ of currently married women had experienced some form of IPV in the last 12 months. Various studies in Nepal reported large ranges of prevalence of IPV, which may be due to differences in the study population, sample size, and geographic area covered. ${ }^{3,4,23}$ Women with no education, who had manual jobs, whose husbands had manual jobs, and women from poor economic status

Table 2 Distribution of women and prevalence of any IPV and STI in the last 12 months by husband's background characteristics (NDHS 201 I) $)^{6,32}$

\begin{tabular}{|c|c|c|c|c|c|}
\hline \multirow{2}{*}{$\begin{array}{l}\text { Background } \\
\text { characteristics }\end{array}$} & \multicolumn{2}{|l|}{ Any IPV } & \multirow[t]{2}{*}{$P$-value } & \multirow{2}{*}{$\begin{array}{l}\text { STI } \\
\%(95 \% \mathrm{Cl})\end{array}$} & \multirow[t]{2}{*}{$P$-value } \\
\hline & Total n (\%) & $\%(95 \% \mathrm{Cl})$ & & & \\
\hline \multicolumn{6}{|l|}{ Husband's occupation } \\
\hline Agriculture & $920(29.8 I)$ & I5.7| (|2.7I, |9.26) & 0.0001 & $13.60(10.83,16.94)$ & 0.7491 \\
\hline Professional & $543(17.6 I)$ & II.52 (8.56, I5.34) & & I4.49 (I0.3।, I9.98) & \\
\hline Sales/services & $779(25.26)$ & 9.79 (7.89, I2.08) & & $14.49(\mid 1.85,17.60)$ & \\
\hline Manual & $842(27.31)$ & $19.96(16.75,23.61)$ & & $16.07(\mid 2.78,20.02)$ & \\
\hline \multicolumn{6}{|l|}{ Husband's education } \\
\hline No education & $633(20.55)$ & $20.74(16.99,25.07)$ & 0.0001 & I5.63 (II.98, 20.15) & 0.7734 \\
\hline Primary & $693(22.47)$ & I8.53 (I4.7I, 23.07) & & $|3.8|(|0.54| 7.9)$, & \\
\hline Secondary/higher & I,758 (56.99) & $10.9(9.16,12.91)$ & & I4.64 (I2.65, I6.88) & \\
\hline \multicolumn{6}{|c|}{ Husband's alcohol use } \\
\hline No & I,484 (48.I I) & $8.57(6.59,11.08)$ & 0.0001 & I3.67 (I I.43, I6.27) & 0.3066 \\
\hline Yes & $\mathrm{I}, 600$ (5I.89) & $20.26(18.08,22.62)$ & & I5.57 (I2.95, I8.60) & \\
\hline \multicolumn{6}{|l|}{ Other wives } \\
\hline No & $2,969(96.18)$ & $14.34(12.79,16.03)$ & 0.0465 & $14.72(|2.9|, \mid 6.73)$ & 0.6950 \\
\hline Yes & $115(3.73)$ & $22.34(14.46,32.88)$ & & $13.09(7.07,22.95)$ & \\
\hline
\end{tabular}

Note: Taylor linearization method was used to estimate the standard error and $P$-value was calculated by Pearson chi-squared test.

Abbreviations: $\mathrm{Cl}$, confidence interval; IPV, intimate partner violence; NDHS, Nepal Demographic Health Survey; STI, sexually transmitted infection. 
Table 3 Association between IPV and STI in the last 12 months (NDHS 20I I $)^{6,32}$ for women

\begin{tabular}{llll}
\hline Any IPV & Total $\mathbf{n}(\%)$ & $\%(95 \%$ CI) & P-value \\
\hline Yes & $45 I(14.64)$ & $23.01(17.76,29.25)$ & 0.0001 \\
No & $2633(85.36)$ & $13.22(11.49,15.18)$ & \\
\hline
\end{tabular}

Note: Taylor linearization method was used to estimate the standard error and $P$-value was calculated by Pearson chi-squared test.

Abbreviations: $\mathrm{Cl}$, confidence interval; IPV, intimate partner violence; NDHS, Nepal Demographic Health Survey; STI, sexually transmitted infection.

Table 4 Multiple logistic regression model of getting STI for any IPV and other background characteristics among currently married Nepalese women (NDHS 20I I)

\begin{tabular}{|c|c|c|}
\hline & Adjusted odds ratio & $95 \% \mathrm{Cl}$ \\
\hline \multicolumn{3}{|l|}{ Any violence } \\
\hline No & $\mathrm{I}$ & \\
\hline Yes & $1.88 * *$ & $1.29,2.73$ \\
\hline Age of women (in years) & 1.00 & $0.98,1.02$ \\
\hline \multicolumn{3}{|l|}{ Caste } \\
\hline Brahmin/Chhetri & I & \\
\hline Janajati & 0.71 & $0.50,1.02$ \\
\hline Dalit & 1.44 & $0.90,2.31$ \\
\hline Other Terai caste & 1.08 & $0.47,2.48$ \\
\hline Muslim & 0.80 & $0.39,1.68$ \\
\hline \multicolumn{3}{|l|}{ Place of residence } \\
\hline Urban & $\mathrm{I}$ & \\
\hline Rural & 0.91 & $0.63,1.30$ \\
\hline \multicolumn{3}{|l|}{ Ecological region } \\
\hline Mountain & $\mathrm{I}$ & \\
\hline Hill & 1.29 & $0.87,1.91$ \\
\hline Terai & 0.99 & $0.67,1.49$ \\
\hline \multicolumn{3}{|l|}{ Development region } \\
\hline Eastern & 1 & \\
\hline Central & $0.69 *$ & $0.48,0.98$ \\
\hline Western & 0.68 & $0.44,1.05$ \\
\hline Mid-western & $0.61^{*}$ & $0.39,0.95$ \\
\hline Far-western & $0.4 I^{* *}$ & $0.24,0.69$ \\
\hline \multicolumn{3}{|l|}{ Economic status } \\
\hline Poor & I & \\
\hline Not poor & 1.38 & $0.98,1.96$ \\
\hline \multicolumn{3}{|l|}{ Number of marriage } \\
\hline Once & I & \\
\hline More than once & $2.50 * *$ & $1.59,3.91$ \\
\hline \multicolumn{3}{|c|}{ Attitude towards negotiation for safer sex } \\
\hline Positive & I & \\
\hline Negative & 0.75 & $0.43,1.31$ \\
\hline \multicolumn{3}{|l|}{ Women's occupation } \\
\hline No work & I & \\
\hline Professional & 1.26 & $0.61,2.59$ \\
\hline Sales & 1.16 & $0.70,1.94$ \\
\hline Manual & 1.00 & $0.51,1.94$ \\
\hline Agriculture & 1.18 & $0.73,1.91$ \\
\hline \multicolumn{3}{|l|}{ Women's education } \\
\hline No education & I & \\
\hline Primary & $0.65 *$ & $0.46,0.93$ \\
\hline Secondary or higher & 0.90 & $0.58,1.41$ \\
\hline
\end{tabular}

Notes: $* P<0.05 ; * * P<0.01$; values for male circumstances were not presented in the table.

Abbreviations: $\mathrm{Cl}$, confidence interval; IPV, intimate partner violence; NDHS, Nepal Demographic Health Survey; STI, sexually transmitted infection. experienced more IPV and the result was consistent with other studies demonstrating lower socioeconomic status as important risk factor for IPV for women..$^{24}$ Various studies reported drinking habits of husbands as a risk factor for IPV not only in the period of intoxication but also when they are sober. ${ }^{25,26}$ This study also found a higher prevalence of IPV among women whose husbands drank alcohol compared to those whose husbands did not drink alcohol.

Interview accompanied with a structured questionnaire, trained interviewers, and ensuring the privacy and confidentiality of the information were the strengths of this study. Information about IPV was collected based on specific acts, such as "threat to harm" or "perform the unwanted sexual acts" instead of subjective judgment about violence. Information about STI was collected using proxy measures; eg, disease through sexual contact or genital ulcers and bad-smelling abnormal vaginal discharge. This increased the chance of reporting an STI by minimizing the stigma associated with the term STI. In Nepal, access to diagnostic services is limited and women often do not know the name of the disease they have. However, they are aware of the symptoms they have. Though symptoms like foul-smelling unusual vaginal discharge may occur in conditions other than STI, in a country like Nepal where prevalence of STI is high, it is usually a symptom of common STIs. ${ }^{27}$ Prevalence of IPV reported in this study was lower than in other studies in Nepal..$^{3-5,23}$ Higher levels of IPV in small studies may be due to differences in study population, geographic area, and the size of the studies. ${ }^{3,4,23}$ This study covered the entire country and all ethnic groups, whereas other studies were based on few districts and only some major ethnic groups.

Though the interviewer-administered survey is the most common and practiced method of data collection about IPV, due to social desirability bias introduced by the methodology, underreporting of IPV is common. ${ }^{28}$ IPV and STI are stigmatized and sensitive issues and collection of valid and accurate information is challenging. ${ }^{20}$ Disclosing violence by the husband in the home is quite difficult because of the culture of silence around all acts of male and normalization of violence against females. Hence, IPV has probably been underreported and would thus lead to low power to detect the association. Due to the cross-sectional character of the study, no causal inferences could be made. A further limitation of this study might be that since STI is a treatable condition and can occur frequently, it might not be recalled when asked.

Though Nepal has ratified various international and regional conventions regarding protection of women's rights and implemented various policy and programs to improve the status of 
women, large proportions of women still suffer from violence and violence-related health complications. This study added evidence on the relationship of reproductive health consequences and IPV against women. Programs and policies have been implemented very poorly. ${ }^{5}$ A high prevalence of IPV among currently married women and a higher risk of STI among women exposed to IPV as shown by this study indicates the necessity of integration between health and violence control policies and programs. Various studies have suggested general screening of patients for IPV as one of the important interventions in the health sector to improve health of women. ${ }^{9,29}$ In the setting where access to the health and other social services is limited as in Nepal, the health service will be the only setting where clients can be offered counseling, care, and perhaps protection services. ${ }^{30}$ Abused women should be considered for STI screening and STI patients should be assessed for violent relationships. Training health workers to ask appropriate screening questions, identify physical signs of abuse, and give support to establish links between clients and counseling, shelters and community based organizations may be an effective intervention to reduce the burden of IPV and STI. ${ }^{31}$ Study findings suggest that IPV prevention and control programs should be implemented on the community level targeting poor and uneducated communities.

\section{Conclusion}

This study found that women who reported IPV in the last 12 months were more likely to report sexually transmitted infections, which is consistent with the association found at the international level. This study also revealed that about 15\% of women who experienced IPV in the last 12 months and one in four women who had IPV in the last 12 months reported at least one sign and symptom of STIs. Hence, risk of IPV should be assessed among clients of reproductive health clinics and screening of STIs should be carried out among victims of IPV. Programs and policies targeted to intimate partner violence and reproductive health should be integrated with each other.

\section{Disclosure}

The authors report no conflicts of interest in this work.

\section{References}

1. Krug EG, Dahlberg LL, Mercy JA, Zwi AB, Lozano R. World Report on Violence and Health. Geneva: World Health Organization; 2002.

2. Ellsberg M, Jansen HA, Heise L, Watts CH, Garcia-Moreno C; WHO Multi-country Study on Women's Health and Domestic Violence against Women Study Team. Intimate partner violence and women's physical and mental health in the WHO multi-country study on women's health and domestic violence: an observational study. Lancet. 2008;371(9619):1165-1172.
3. Puri M, Frost M, Tamang J, Lamichhane P, Shah I. The prevalence and determinants of sexual violence against young married women by husbands in rural Nepal. BMC Res Notes. 2012;5:291.

4. Adhikari R, Tamang J. Sexual coercion of married women in Nepal. BMC Womens Health. 2010;10:31.

5. Office of the Prime Minister and Council of Ministers. A Study on GenderBased Violence Conducted in Selected Rural Districts of Nepal. Kathmandu: Office of the Prime Minister and Council of Ministers; 2012.

6. Ministry of Health and Population (MOHP) [Nepal], New ERA, Macro International Inc. Nepal Demographic Health Survey 2011. Kathmandu: Ministry of Health and Population, New ERA, and ICF International; 2012.

7. Kishor S. Married women's risk of STIs in developing countries: the role of intimate partner violence and partner's infection status. Violence Against Women. 2012;18(7):829-853.

8. McFarlane J, Parker B, Soeken K. Abuse during pregnancy: associations with maternal health and infant birth weight. Nurs Res. 1996;45(1):37-42.

9. Campbell JC. Health consequences of intimate partner violence. Lancet. 2002;359(9314):1331-1336.

10. Black MC. Intimate partner violence and adverse health consequences: implications for clinicians. Am J Lifestyle Med. 2011;5(5):428-439.

11. Ludermir AB, Schraiber LB, D'Oliveira AF, França-Junior I, Jansen HA. Violence against women by their intimate partner and common mental disorders. Soc Sci Med. 2008;66(4):1008-1018.

12. Sillito CL. Physical health effects of intimate partner abuse. J Fam Issues. 2012;33(11):1520-1539.

13. Coker AL. Does physical intimate partner violence affect sexual health? A systematic review. Trauma, violence \& abuse. Apr 2007;8(2): 149-177.

14. Hess KL, Javanbakht M, Brown JM, Weiss RE, Hsu P, Gorbach PM. Intimate partner violence and sexually transmitted infections among young adult women. Sex. Transm. Dis. May 2012;39(5):366-371.

15. Lockart I, Ryder N, McNulty AM. Prevalence and associations of recent physical intimate partner violence among women attending an Australian sexual health clinic. Sex Transm Infect. 2011;87(2):174-176.

16. Seth P, Raiford JL, Robinson LS, Wingood GM, Diclemente RJ. Intimate partner violence and other partner-related factors: correlates of sexually transmissible infections and risky sexual behaviours among young adult African American women. Sex Health. 2010;7(1):25-30.

17. Díaz-Olavarrieta C, Wilson KS, García SG, et al. The co-occurrence of intimate partner violence and syphilis among pregnant women in Bolivia. J Womens Health (Larchmt). 2009;18(12):2077-2086.

18. Allsworth JE, Anand M, Redding CA, Peipert JF. Physical and sexual violence and incident sexually transmitted infections. $J$ Womens Health (Larchmt). 2009;18(4):529-534.

19. Tuladhar S, Khanal KR, Lila KC, Ghimire PK, Onta K. Women's Empowerment and Spousal Violence in Relation to Health Outcomes in Nepal: Further Analysis of the 2011 Nepal Demographic and Health Survey. Calverton: Nepal Ministry of Health and Population, New ERA, and ICF International; 2013.

20. Dhakal S, van Teijlingen E, Raja EA, Dhakal KB. Skilled care at birth among rural women in Nepal: practice and challenges. J Health Popul Nutr. 2011;29(4):371-378.

21. Laanpere M, Ringmets I, Part K, Karro H. Intimate partner violence and sexual health outcomes: a population-based study among 16-44-yearold women in Estonia. Eur J Public Health. 2013;23(4):688-693.

22. Rahman M, Nakamura K, Seino K, Kizuki M. Intimate partner violence and symptoms of sexually transmitted infections: Are the women from low socio-economic strata in Bangladesh at increased risk. Int J Behav Med. 2013.

23. Lamichhane P, Puri M, Tamang J, Dulal B. Women's status and violence against young married women in rural Nepal. BMC Womens Health. 2011;11:19.

24. Antai D. Controlling behavior, power relations within intimate relationships and intimate partner physical and sexual violence against women in Nigeria. BMC Public Health. 2011;11:511. 
25. Bacchus L, Mezey G, Bewley S. A qualitative exploration of the nature of domestic violence in pregnancy. Violence Against Women. 2006;12(6):588-604.

26. Muhajarine N, D’Arcy C. Physical abuse during pregnancy: prevalence and risk factors. CMAJ. 1999;160(7):1007-1011.

27. National Centre for AIDS and STD Control. National Guidelines on Case Management of Sexually Transmitted Infections. Kathmandu, Nepal: NCASC; 2009.

28. Ismayilova L, El-Bassel N. Prevalence and correlates of intimate partner violence by type and severity: population-based studies in Azerbaijan, Moldova, and Ukraine. J Interpers Violence. 2013;28(12): 2521-2556.

29. Garcia-Moreno C, Jansen HA, Ellsberg M, Heise L, Watts CH; WHO Multi-country Study on Women's Health and Domestic Violence against Women Study Team. Prevalence of intimate partner violence: findings from the WHO multi-country study on women's health and domestic violence. Lancet. 2006;368(9543):1260-1269.
30. Augenbraun M, Wilson TE, Allister L. Domestic violence reported by women attending a sexually transmitted disease clinic. Sex Transm Dis. 2001;28(3):143-147.

31. Bauer HM, Gibson P, Hernandez M, Kent C, Klausner J, Bolan G. Intimate partner violence and high-risk sexual behaviors among female patients with sexually transmitted diseases. Sex Transm Dis. 2002;29(7): 411-416.

32. Measure DHS [Nepal: Standard DHS, 2011]. Demographic and Health surveys (DHS). Available from: https://www.measuredhs.com/data/ dataset/Nepal_Standard-DHS_2011.cfm?flag=1. Accessed on January $16,2014$.

\section{Publish your work in this journal}

The International Journal of Women's Health is an international, peerreviewed open-access journal publishing original research, reports, editorials, reviews and commentaries on all aspects of women's healthcare including gynecology, obstetrics, and breast cancer. The manuscript management system is completely online and includes a very quick and fair peer-review system, which is all easy to use. Visit http://www.dovepress.com/testimonials.php to read real quotes from published authors.

Submit your manuscript here: http://www.dovepress.com/international-journal-of-womens-health-journal 